\title{
ATP-independent Thermoprotective Activity of Nicotiana tabacum Heat Shock Protein 70 in Escherichia coli
}

\author{
Eun Kyung Cho ${ }^{1, *}$ and Song-Ja Bae ${ }^{2,3}$ \\ ${ }^{1}$ Department of Bio-Food Materials, College of Medical Life Science, Silla University, Busan 617-736, Korea \\ ${ }^{2}$ Department of Food and Nutrition, College of Medical Life Science, Silla University, Busan 617-736, Korea \\ ${ }^{3}$ Marine Biotechnology Center for Bio-Functional Material Industries, Silla University, Busan 617-736, Korea
}

Received 21 July 2006, Accepted 22 September 2006

\begin{abstract}
To study the functioning of HSP70 in Escherichia coli, we selected NtHSP70-2 (AY372070) from among three genomic clones isolated in Nicotiana tabacum. Recombinant NtHSP702, containing a hexahistidine tag at the amino-terminus, was constructed, expressed in $E$. coli, and purified by $\mathrm{Ni}^{2+}$ affinity chromatography and $Q$ Sepharose Fast Flow anion exchange chromatography. The expressed fusion protein, H$_{6}$ NtHSP70-2 (hexahistidine-tagged Nicotiana tabacum heat shock protein 70-2), maintained the stability of $E$. coli proteins up to $90^{\circ} \mathrm{C}$. Measuring the light scattering of luciferase (luc) revealed that $\mathrm{NtHSP70-2}$ prevents the aggregation of luc without ATP during high-temperature stress. In a functional bioassay $\left(1 \mathrm{~h}\right.$ at $\left.50^{\circ} \mathrm{C}\right)$ for recombinant $\mathrm{H}_{6} \mathrm{NtHSP70-2}$ E. coli cells overexpressing $\mathrm{H}_{6} \mathrm{NtHSP70-2}$ survived about seven times longer than those lacking $\mathrm{H}_{6} \mathrm{NtHSP70-2}$. After $2 \mathrm{~h}$ at $50^{\circ} \mathrm{C}$, only the $E$. coli overexpressing $\mathrm{H}_{6} \mathrm{NtHSP70-2}$ survived under such conditions. Our NtHSP70-2 bioassays, as well as in vitro studies, strongly suggest that HSP70 confers thermo-tolerance to $E$. coli.
\end{abstract}

Keywords: Escherichia coli, Heat shock protein 70 (HSP70), in vivo and in vitro Functioning, Nicotiana tabacum, Thermotolerance

\section{Introduction}

Under stress conditions, molecular chaperones cooperate in vitro as part of a functional network in which the chaperones

\footnotetext{
Abbreviations: $\mathrm{H}_{6} \mathrm{NtHSP70-2}$, hexahistidine-tagged Nicotiana tabacum heat shock protein 70-2; luc, luciferase
}

*To whom correspondence should be addressed.

Tel: 82-51-999-6242, Fax: 82-51-999-5176

E-mail: choeun@silla.ac.kr prevent the aggregation of misfolded proteins, while actively assist in their refolding (Veinger et al., 1998; Bukau and Horwich, 1999; Mogk et al., 1999; Mayer et al., 2001; Lee and Tsai, 2005). The contributions of individual chaperones to this folding network and the identity of such stress-sensitive cellular proteins are not well known. Therefore, it is important that the extent of which chaperones can re-solubilize aggregates of proteins that escape the protection of holder chaperones is determined (Tatsuta et al., 1998; Mayer et al., 2001; Tomoyasu et al., 2001).

Here, we investigated heat shock protein 70 (HSP70), a molecular chaperone that helps protect cellular proteins. The mechanistic aspects of the HSP70 system have been extensively studied with DnaK (a representative Hsp70), DnaJ (a member of the HSP40 family), and GrpE (a type of co-chaperone) from Escherichia coli. According to the study, DnaJ is believed to stabilize the binding of DnaK to the substrate by stimulating the hydrolysis of DnaK-bound ATP. GrpE plays a crucial role in releasing the folding substrates from DnaK (Mayer et al., 2000; Groemping and Reinstein, 2001; Hartl and Hayer-Hartl, 2002; Tanaka et al., 2002; Mayer and Bukau, 2005). Therefore, DnaJ, GrpE, and ATP are essential to this HSP70 chaperone action. However, this theory has been redefined in kinetic studies of HSP70 and substrates in the absence of co-chaperones such as DnaJ and GrpE. For example, the activity of HSP70 was unaffected by physiological levels of HSP40 and GrpE in vivo (Michels et al., 1997; Nollen et al., 1999; Silberg and Vickery, 2000; Mayer and Bukau, 2005). Although suggesting a new functional mode for HSP70 as mentioned above, HSP70 has still been reported as ATP-dependent chaperone (Haslbeck et al., 2005; Tuttle, 2006). Therefore, investigation for action of ATP-independent HSP70 have a great value.

Although the functioning of HSP70 has been enhanced in plant systems (Luft and Dix, 1999; Lee and Vierling, 2000; Efremova et al., 2002; Cho and Hong, 2004; Liu et al., 2005), no reports have been made that this protein, in the absence of 
co-chaperones or co-factor, can contribute to the protection of substrates from thermal aggregation in vitro. In the study presented here, we investigated the role of tobacco HSP70 isolated from Nicotiana tabacum to determine whether it acts as a molecular chaperone in vitro and in vivo and whether ATP and co-chaperones are necessary for HSP70 activity. The tobacco HSP70 NtHSP70-2 has high homology with other HSP70s, and shows a typical heat shock-responsive expression pattern (Cho and Hong, 2004). This suggests that NtHSP70-2 can function as a molecular chaperone under high temperatures. Therefore, to examine the functions of plant HSP70, we constructed a recombinant gene encoding NtHSP70-2 with a hexahistidine tag at the amino terminus, and then expressed it in E. coli. Cells in which NtHSP70-2 was over-expressed showed enhanced survival at high temperatures.

\section{Materials and Methods}

Bacterial strains, chemicals, and plasmid. E. coli strain DH5 $\alpha$ was used in the construction of recombinant DNA, and the strain MC1061 was used for the expression of recombinant proteins. Recombinant NtHSP70-2 was expressed in E. coli with pBADNH (Cho et al., 2005). Ni-NTA matrices from Qiagen and Q Sepharose Fast Flow from Amersham Biosciences were employed for the purification of $6 \mathrm{X}$ His-tagged proteins. The dye reagent for protein quantitation was from Bio-Rad; DNA modifying enzymes, Taq DNA polymerase, and DNA ligase, from Promega; and all chemicals from Sigma, unless otherwise mentioned.

Construction of an $E$. coli NtHSP70-2 expression vector. To prepare an E. coli $\mathrm{H}_{6} \mathrm{NtHSP70-2}$ expression construct, the NtHSP702 open reading frame was amplified by PCR, using primers covering both termini of the NtHSP70-2 coding region, which encodes a full-length polypeptide of 653 amino acids. The 5' primer was 5' AAAAAAAAGCTTATGGGTCCCGCCGTC3' and the 3' primer was 5'AAAGGGAAGCTTTTAGTCGACCTCCTC3'. HindIII restriction sites (underlined) were included in the primers. The amplified product was digested with HindIII and ligated into the pBADNH expression vector between the HindIII sites to produce $\mathrm{H}_{6} \mathrm{NtHSP70-2}$. The nucleotide sequence of the coding region fused into pBADNH was confirmed with an Applied Biosystems 3730 automatic sequencer. Nucleotide and deduced amino acid sequences were compared with contents in the GenBank and Swiss-Prot databases.

Expression and purification of $\mathbf{H}_{\mathbf{6}} \mathbf{N t H S P 7 0 - 2}$. The above expression construct was transformed into $E$. coli strain MC1061, grown at $37^{\circ} \mathrm{C}$ to the mid-log phase $(\mathrm{A} 600=0.5)$ in an LB medium containing ampicillin. Exponentially growing cells were induced by adding $0.2 \%(\mathrm{w} / \mathrm{v})$ arabinose, grown for $1 \mathrm{~h} 30 \mathrm{~min}$ at $37^{\circ} \mathrm{C}$, and harvested by centrifugation at $10,000 \mathrm{~g}$ for $5 \mathrm{~min}$. The pellet was re-suspended in protein extraction lysis buffer $\left(50 \mathrm{mM} \mathrm{NaH}_{2} \mathrm{PO}_{4}, 300 \mathrm{mM} \mathrm{NaCl}\right.$, and $20 \mathrm{mM}$ imidazole), then sonicated (total processing time 10 min, pulse-on time $3 \mathrm{~s}$, pulse-off time $12 \mathrm{~s}$ ), and centrifuged at $15,000 \mathrm{~g}$ for $25 \mathrm{~min}$. NtHSP70-2 expressing cells were separated into soluble and insoluble proteins by centrifugation, and suspended in loading buffer for electrophoresis on 12\% SDS-PAGE gels. Soluble $\mathrm{H}_{6} \mathrm{NtHSP} 70-2$ was partially purified on a $\mathrm{Ni}^{2+}$ affinity column using washes with 20 and $40 \mathrm{mM}$ imidazole and elution with $250 \mathrm{mM}$ imidazole. Fractions containing the eluted $\mathrm{H}_{6} \mathrm{NtHSP} 70-2$ were applied to a Q Sepharose Fast Flow anion exchange chromatography column and eluted at a linear gradient of 40 to 400 $\mathrm{mM} \mathrm{NaCl}$ in protein buffer ( $25 \mathrm{mM}$ Tris-Cl and $1 \mathrm{mM}$ EDTA).

Thermal stability of proteins in $\boldsymbol{E}$. coli cell lysates. E. coli cell lysates either containing or lacking $\mathrm{H}_{6} \mathrm{NtHSP} 70-2$ were prepared as described above, with exponentially growing cells induced for $1 \mathrm{~h}$ $30 \mathrm{~min}$ at $37^{\circ} \mathrm{C}$. The proteins in the lysates were diluted to $3 \mathrm{mg} \mathrm{ml}^{-1}$ in lysis buffer. Samples $(100 \mu \mathrm{l})$ of the diluted lysates were layered with mineral oil and incubated for $15 \mathrm{~min}$ at 30 to $100^{\circ} \mathrm{C}$ in a circulating water bath (Polyscience Co.). The lysates were then allowed to cool to room temperature, the mineral oil was removed, and the samples were centrifuged at $15,000 \mathrm{~g}$ for $10 \mathrm{~min}$ to remove the denatured proteins. The supernatants were analyzed on $12 \%$ SDS-polyacrylamide gels (Sambrook et al., 1989).

In vitro molecular chaperone activity of NtHSP70-2. Thermally induced aggregation of luc (Sigma) was examined to determine the molecular chaperone activity of NtHSP70-2. Luc (200 nM) was incubated under heat shock $\left(42^{\circ} \mathrm{C}\right)$ either alone or in the presence of 20 to $120 \mathrm{nM}$ purified $\mathrm{H}_{6} \mathrm{NtHSP} 70-2$ in a buffer containing $25 \mathrm{mM}$ Tris (pH 7.5), $1 \mathrm{mM}$ EDTA, and $25 \mathrm{mM} \mathrm{KCl}$ (total volume $0.5 \mathrm{ml}$ ), and with or without $2 \mathrm{mM}$ of ATP. Absorbance at $340 \mathrm{~nm}$ was monitored at 2.5-min intervals using the kinetics mode of a WinSpec spectrophotometer (Spectronic Instrument Inc.).

Cell viability. To measure cell viability under high temperatures, exponentially growing $E$. coli cells transformed with pBADNH/ NtHSP70-2 or pBADNH were cultured with $0.2 \%(\mathrm{w} / \mathrm{v})$ arabinose for $8 \mathrm{~h}$ at $28^{\circ} \mathrm{C}$, then incubated at $50^{\circ} \mathrm{C}$. Aliquots $(100 \mu \mathrm{l})$ of the cultures were taken at $1,2,3$, and $4 \mathrm{~h}$ after their transfer to $50^{\circ} \mathrm{C}$, and serial dilutions were plated on LB agar containing ampicillin. Their viability was determined by counting the colony forming units (CFU) after the plates were incubated overnight at $37^{\circ} \mathrm{C}$. These counts were plotted as the percentage of CFUs formed after heat treatment relative to the number of CFUs formed in equivalent, untreated cultures.

\section{Results}

Expression in $E$. coli and purification of NtHSP70-2. For our functional analysis, the NtHSP70-2 coding region was inserted into the $E$. coli expression vector $\mathrm{pBADNH}$ to produce a $\mathrm{H}_{6} \mathrm{NtHSP} 70-2$ (Fig. 1). E. coli cells containing pBADNH/NtHSP70-2 were treated with arabinose to induce production of the fusion protein, and expression was confirmed by SDS-PAGE. Overexpression of $\mathrm{H}_{6} \mathrm{NtHSP70-2}$ in $E$. coli at $37^{\circ} \mathrm{C}$ for $1 \mathrm{~h} 30 \mathrm{~min}$ resulted in the production of a soluble protein of about $72 \mathrm{kDa}$, which corresponded to the $\mathrm{H}_{6} \mathrm{NtHSP70-2}$. The protein was purified by Ni-NTA affinity chromatography. To obtain more purified $\mathrm{H}_{6} \mathrm{NtHSP70-2,} \mathrm{Q}$ Sepharose Fast Flow anion exchange chromatography was 


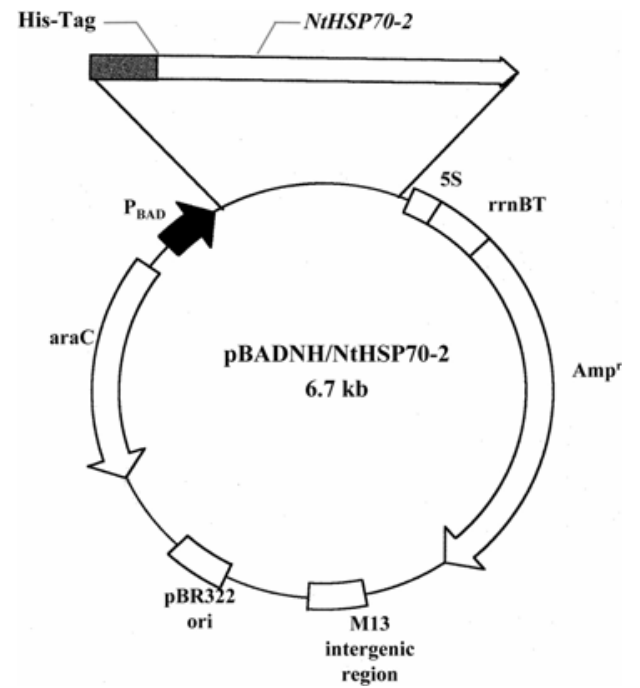

Fig. 1. Map of plasmid constructed to overexpress $\mathrm{H}_{6} \mathrm{NtHSP} 70-2$ in E. coli.

\section{A B}

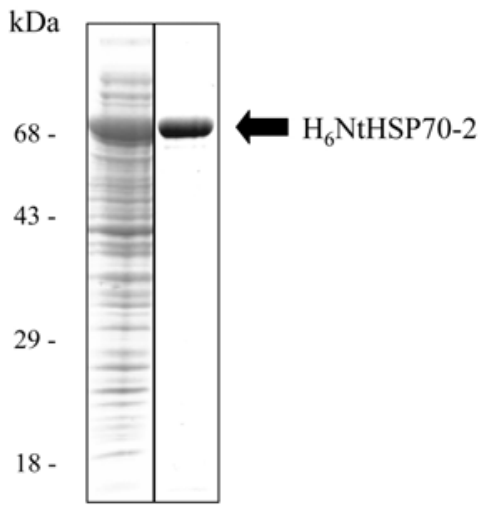

Fig. 2. Overexpression and purification of $\mathrm{H}_{6} \mathrm{NtHSP} 70-2$. Proteins were analyzed on $12 \%$ SDS-PAGE gel and stained with Coomassie Brilliant Blue. (A) Lysate of E. coli cells cultured with $0.2 \%$ arabinose. (B) $\mathrm{H}_{6} \mathrm{NtHSP} 70-2$ purified by $\mathrm{Ni}^{2+}$ affinity chromatography and Q Sepharose Fast Flow anion exchange chromatography.

performed. $\mathrm{H}_{6} \mathrm{NtHSP} 70-2$ was clarified in 320 to $360 \mathrm{mM}$ $\mathrm{NaCl}$ solutions, achieving $>\mathbf{9 0 \%}$ purity (Fig. 2). After dialysis in TE buffer, this protein was used for further functional analysis.

In vitro chaperone activity of NtHSP70-2. Recombinant NtHSP70-2 was assayed in vitro for molecular chaperone activity. Crude $E$. coli extracts were heated and centrifuged to remove heat-denatured and aggregated proteins.

Differences were observed in crude extracts from cells carrying the empty vector versus those that overproduced $\mathrm{H}_{6} \mathrm{NtHSP70-2}$ when both were grown at $50^{\circ} \mathrm{C}$, i.e., the temperature that usually induces bacterial cell lysis (Fig. 3). Under such conditions, about $70 \%$ of the proteins in lysates
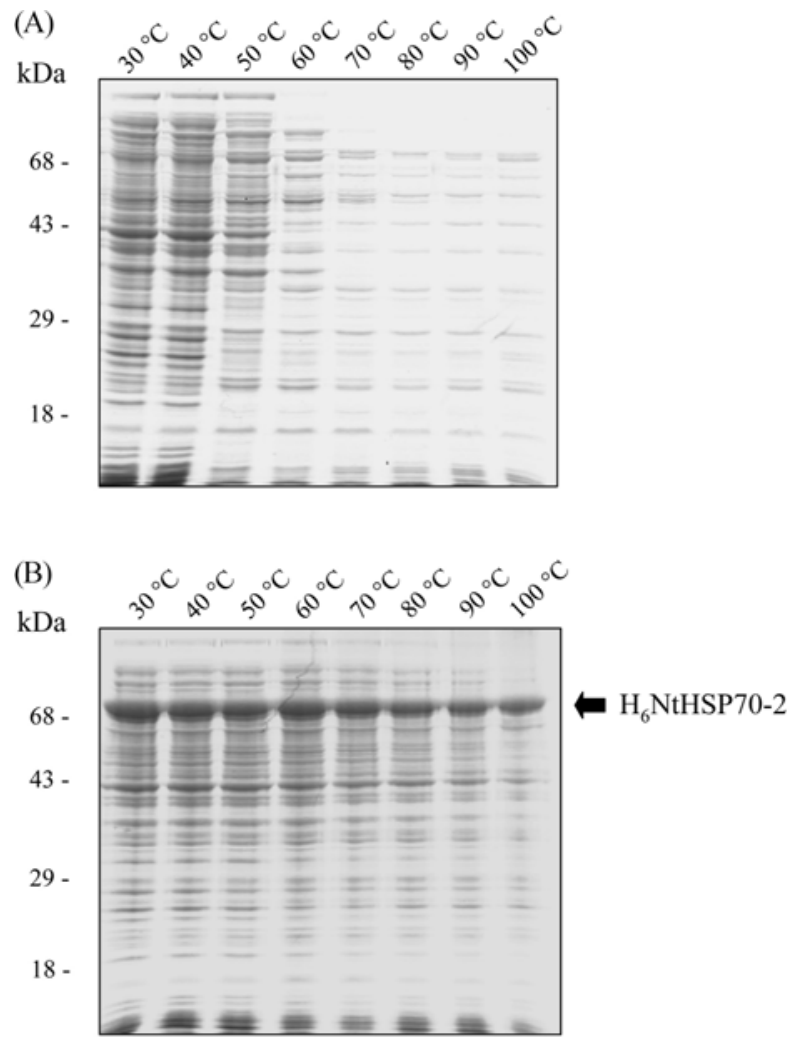

Fig. 3. Effect of $\mathrm{H}_{6} \mathrm{NtHSP} 70-2$ on the thermal stability of proteins in E. coli. Cell lysates lacking (A) or containing (B) $\mathrm{H}_{6} \mathrm{NtHSP} 70-2$ were incubated at $30,40,50,60,70,80,90$, or $100^{\circ} \mathrm{C}$ for $15 \mathrm{~min}$, after which the soluble proteins were analyzed on $12 \%$ SDS-PAGE gels.

from cells carrying the empty vector were not protected from aggregation (Fig. 3A), whereas the others were fully protected, remaining stable even at $70^{\circ} \mathrm{C}$ (Fig. 3B). However, $\mathrm{H}_{6} \mathrm{NtHSP70-2}$ was less stable at temperatures greater than $70^{\circ} \mathrm{C}$, leading to the aggregation of the other cellular proteins.

Thermal protection of aggregation of luc by NtHSP70-2. The molecular chaperone activity of NtHSP70-2 was examined by monitoring the protection of aggregation of luc by the protein under thermal stress. A concentration-dependent effect was observed in vitro by measuring the light scattering of luc at $42^{\circ} \mathrm{C}$. At $42^{\circ} \mathrm{C}$ and without any NtHSP70-2, $200 \mathrm{nM}$ of luc started to aggregate rapidly in the first $5 \mathrm{~min}$, with saturation being nearly complete after $40 \mathrm{~min}$. In the absence of $2 \mathrm{mM}$ ATP, $20 \mathrm{nM}$ (only $10 \%$ of the control level of Luc) NtHSP702 was apparently able to reduce the aggregation of luc to $80 \%$ relative to the level aggregated when NtHSP70-2 was lacking. As the molar ratio of luc to NtHSP70-2 rose, relative light scattering decreased. When the ratio reached $1: 0.4$, the scattering percentage dropped to about $27 \%$; at $1: 0.5$, the percentage was approximately $3 \%$. For luc to NtHSP70-2 ratios of more than $1: 0.5$, e.g., $1: 1$, no additional protective activity was observed. In the presence of $2 \mathrm{mM}$ ATP, samples containing 
(A)

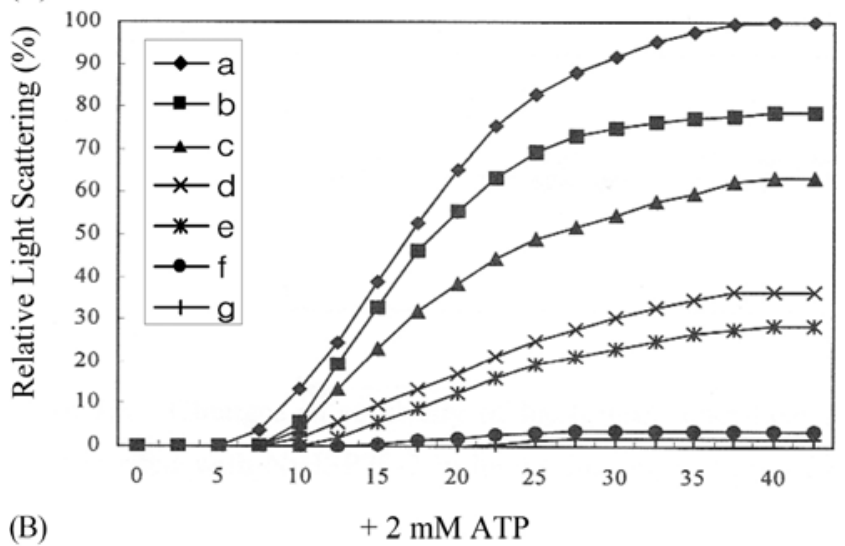

(B)

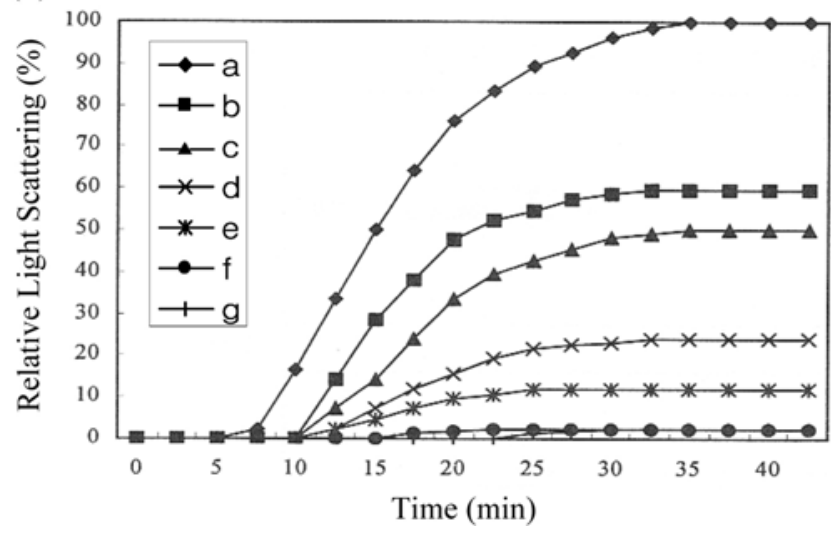

Fig. 4. Suppression of thermal aggregaion of luciferase by $\mathrm{H}_{6} \mathrm{NtHSP70-2}$. Light scattering of aggregated Luc was defined according to absorbance at $340 \mathrm{~nm}$. Luc $(200 \mathrm{nM})$ was heated at $42^{\circ} \mathrm{C}$ with 20 to $120 \mathrm{nM} \mathrm{H}_{6} \mathrm{NtHSP} 70-2$, without ATP (A) or with ATP (B): a, $200 \mathrm{nM} \mathrm{Luc;} \mathrm{b,} 200 \mathrm{nM} \mathrm{Luc}+20 \mathrm{nM} \mathrm{H} \mathrm{H}_{6} \mathrm{NtHSP} 70-2$;

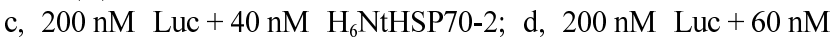
$\mathrm{H}_{6} \mathrm{NtHSP} 70-2 ; \mathrm{e}, 200 \mathrm{nM}$ Luc $+80 \mathrm{nM} \mathrm{H}{ }_{6} \mathrm{NtHSP} 70-2 ;$ f, $200 \mathrm{nM}$ Luc $+100 \mathrm{nM} \mathrm{H} \mathrm{H}_{6} \mathrm{NtHSP70-2}$; g, $200 \mathrm{nM}$ Luc + $120 \mathrm{nM} \mathrm{H}_{6} \mathrm{NtHSP70-}$ 2.

$20 \mathrm{nM}$ NtHSP70-2 reduced the aggregation of luc to $60 \%$ of the level calculated in the absence of NtHSP70-2. Likewise, as the molar ratio of luc to NtHSP70-2 increased, relative light scattering decreased, such that NtHSP70-2 showed stronger activity in the presence of ATP than in its absence. Therefore, these results support the theory that ATP is not necessary for NtHSP70-2 to prevent aggregation of luc. This protein strongly protected aggregation of luc, with its chaperone functioning being proportional to its concentration without ATP. The recombinant NtHSP70-2 also strongly suppressed aggregation of luc under high temperatures (Fig. 4).

In vivo chaperone activity of NtHSP70-2. To investigate the molecular chaperone function of $\mathrm{H}_{6} \mathrm{NtHSP70-2}$ in vivo, the viabilities of $E$. coli cells transformed with $\mathrm{pBADNH} / \mathrm{NtHSP70-}$ 2 or pBADNH were determined at $50^{\circ} \mathrm{C}$. Cells carrying the empty vector (control) were less viable than those overexpressing $\mathrm{H}_{6} \mathrm{NtHSP70-2} \mathrm{(Fig.} \mathrm{5).} \mathrm{Heating} \mathrm{the} \mathrm{pBADNH-containing} \mathrm{cells}$

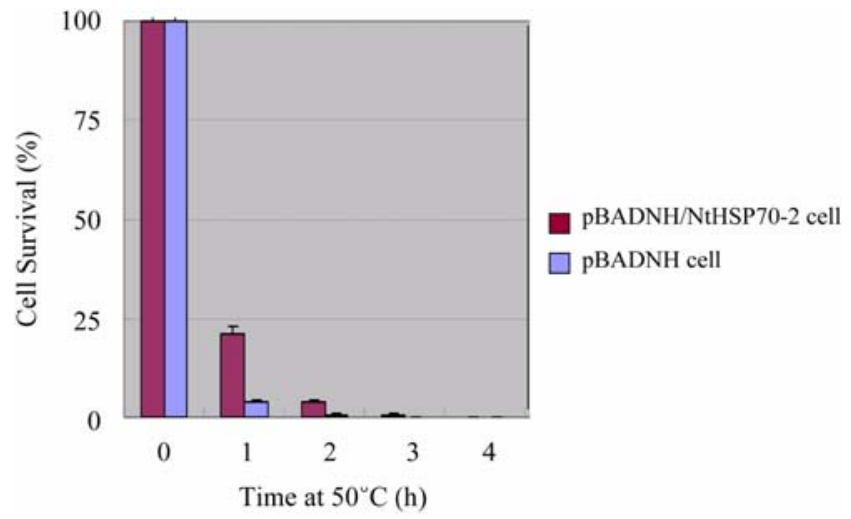

Fig. 5. Influence of $\mathrm{H}_{6} \mathrm{NtHSP} 70-2$ on viability of $E$. coli at $50^{\circ} \mathrm{C}$. Cells carrying pBADNH/NtHSP70-2 or pBADNH were incubated at $50^{\circ} \mathrm{C}$ for $1,2,3$, or $4 \mathrm{~h}$. Viabilities were plotted as percentage of heat-treated colony forming units relative to number of untreated colonies. All data represent means of four independent experiments; error bars indicate standard error.

at $50^{\circ} \mathrm{C}$ for $1 \mathrm{~h}$ resulted in a survival rate of only $3.7 \%$ compared with $21.2 \%$ survival (7-fold higher) for the pBADNH/NtHSP70-2 cells. However, the viabilities of both types of $E$. coli cells, either empty or overproducers, decreased abruptly after $1 \mathrm{~h}$ at $50^{\circ} \mathrm{C}$, so that the viability of our pBADNH/NtHSP70-2 containing cells was 5-fold higher than that of the pBADNH-containing cells. After $2 \mathrm{~h}$, only the over-expressing cells could survive at that high temperature.

\section{Discussion}

The possible functioning of HSP70s as chaperones has been suggested based on protein-folding studies as well as research with $E$. coli and mammalian cells. There, the modes of action have been elucidated mainly through the use of various model systems (Kelley, 1999; Mayer et al., 2001; Abdul et al., 2002; Mayer and Bukau, 2005): E. coli DnaK with the co-chaperones of DnaJ and GrpE (nucleotide exchange factor in bacteria); or via mammalian HSC70 with Hdj-1, the human DnaJ homologue, plus Bag-1 (nucleotide exchange factor in the eukaryotic cytosol). Nevertheless, it has been reported that co-chaperones are not necessary to the action of HSP70 chaperones (Silberg and Vickery, 2000; Kluck et al., 2002), suggesting a different explanation for the cellular functions of HSP70 (Hoff et al., 2000; Brehmer et al., 2001; Silberg et al., 2004). Here, we used $E$. coli to confirm the molecular chaperone activity of NtHSP70-2, a heat shock protein 70 (HSP70) gene isolated from Nicotiana tabacum. Because its mode of action and activities are not yet well known in plant species, our investigation now provides important evidence for the role of plant HSP70 during heat stress (Tanaka et al., 2002; Cho and Hong, 2004; Cho et al., 2005).

Our in vitro experiments first showed that NtHSP70-2 acts as a molecular chaperone (Fig. 3 and 4). Proteins in cell 
lysates that lacked $\mathrm{H}_{6} \mathrm{NtHSP} 70-2$ began to precipitate at $50^{\circ} \mathrm{C}$, whereas those containing $\mathrm{H}_{6} \mathrm{NtHSP} 70-2$ remained fully soluble up to $70^{\circ} \mathrm{C}$, with over $60 \%$ of those continuing to be protected from aggregation to 90 (Fig. 3). We also examined the thermal protection conferred by luc, a heat-labile protein that is the most commonly used model enzyme for in vitro chaperone activity assays. When NtHSP70-2 was mixed with luc, light scattering of the latter was decreased in proportion to the concentration of protein tested (Fig. 4). This result suggests that NtHSP70-2 acts as a molecular chaperone with little substrate specificity under high-temperature stress, while also demonstrating that co-chaperones and ATP are not necessary to the mode of action by NtHSP70-2. Our conclusions agree with those from previous studies, in which the activity of HSP70 was unaffected by the physiological levels of HSP40 and GrpE (Nollen et al., 1999; Silberg and Vickery, 2000). However, more experiments are needed to confirm that only NtHSP70-2 prevents the aggregation of denatured proteins by heat stress.

In our second experiment, E. coli cells overexpressing $\mathrm{NtHSP70-2}$ showed higher survival rates at $50^{\circ} \mathrm{C}$ than did the control cells (Fig. 5). These results, together with those from our in vitro functional analysis, indicate that NtHSP70-2 alone acts to prevent the aggregation of denatured proteins by heat shock. However, the viabilities of E. coli cells carrying the empty vector and those overproducing $\mathrm{H}_{6} \mathrm{NtHSP70-2}$ decreased abruptly after $1 \mathrm{~h}$ at $50^{\circ} \mathrm{C}$, at which point the viability of pBADNH/NtHSP70-2 containing cells was five-fold higher than that of the pBADNH-containing cells. This implies that NtHSP70-2 only weakly assists in the refolding of denatured proteins following heat stress or requires ATP and other cochaperones in protein refolding under stress conditions (Kluck et al., 2002; Silberg et al., 2004). Therefore, more experiments are needed to verify that the activity of NtHSP70-2 is not affected by physiological levels of HSP40, GrpE, and ATP in vivo.

Although we did not demonstrate here the mechanism for a new mode of action by HSP70 in protein-refolding under heat stress, we can conclude that the overexpression of HSP70 alone increases both the level of cellular chaperone activity and the degree of thermo-resistance. In addition, this investigation shows the value of researching a possible new pathway for cellular chaperone activity by HSP70.

\section{References}

Abdul, K., Terada, K., Gotoh, T., Hafizur, R. and Mori, M. (2002) Characterization and functional analysis of a heart-enriched DnaJ/ Hsp40 homolog dj4/DjA4. Cell Stress Chap. 7, 156-166.

Brehmer, D., Rüdiger, S., Gässler, C. S., Klostermeier, D., Packschies, L., Reinstein, J., Mayer, M. P. and Bukau, B. (2001) Tuning of chaperone activity of $\mathrm{Hsp} 70$ proteins by modulation of nucleotide exchange. Nat. Struct. Biol. 8, 427-432.

Bukau, B. and Horwich, A. L. (1999) The Hsp70 and Hsp60 chaperone machines. Cell 692, 351-366.
Cho, E. K. and Hong, C. B. (2004) Molecular cloning and expression pattern analyses of heat shock protein 70 genes from Nicotiana tabacum. J. Plant Biol. 47, 149-159.

Cho, E. K., Lee, Y. K. and Hong, C. B. (2005) A Cyclophilin from Griffithsia japonica has thermoprotective activity and is affected by CsA. Mol. Cells 20, 142-150.

Efremova, S. M., Margulis, B. A., Guzhova, I. V., Itskovich, V. B., Lauenroth, S., Muller, W. E. and Schroder, H. C. (2002) Heat shock protein hsp70 expression and DNA damage in Baikalian sponges exposed to model pollutants and wastewater from Baikalsk Pulp and Paper Plant. Aquat. Toxicol. 57, 267280.

Groemping, Y. and Reinstein, J. (2001) Folding properties of the nucleotide exchanger factor GrpE from Thermus thermophilus: GrpE is a thermosensor that mediates heat shock response. $J$. Mol. Biol. 314, 167-178.

Hartl, F. U. and Hayer-Hartl, M. (2002) Molecular chaperones in the cytosol: From nascent chain to folded protein. Science 295, 1852-1858.

Haslbeck, M., Miess, A., Stromer, T., Walter, S. and Buchner, J (2005) Disassembling protein aggregates in the yeast cytosol; The cooperation of HSP26 with SSA1 and HSP104. J. Biol. Chem. 280, 23861-23868.

Hoff, K. G., Silberg, J. J. and Vickery, L. E. (2000) Interaction of the iron-sulfur cluster assembly protein IscU with the Hsc66/ Hsc20 molecular chaperone system of Escherichia coli. Proc. Natl. Acad. Sci. USA 97, 7790-7795.

Kelley, W. L. (1999) Molecular chaperones: How J domains turn on Hsp70s. Curr. Biol. 22, 305-308.

Kluck, C. J., Patzelt, H., Genevaux, P., Brehmer, D., Rist, W., Schneider-Mergener, J., Bukau, B. and Mayer, B. P. (2002) Structure-function analysis of $\mathrm{HscC}$, the Escherichia coli member of a novel subfamily of specialized Hsp70 chaperones. J. Biol. Chem. 277, 41060-41069.

Lee, G. J. and Vierling, E. (2000) A small heat shock protein cooperates with heat shock protein 70 systems to reactivate a heat-denatured protein. Plant Physiol. 122, 189-198.

Lee, S. Y. and Tsai, F. T. F. (2005) Molecular chaperones in protein quality control. J. Biochem. Mol. Biol. 38, 259-265.

Liu, J. G., Yao, Q. H., Zhang, Z., Peng, R. H., Xiong, A. S., Xu, F. and Zhu, H. (2005) Isolation and characterization of a cDNA encoding two novel heat-shock factor OsHSF6 and OsHSF12 in Oryza Sativa L. J. Biochem. Mol. Biol. 38, 602608.

Luft, J. C. and Dix, D. J. (1999) HSP70 expression and function during embryogenesis. Cell Stress Chap. 4, 162-170.

Mayer, M. P., Brehmer, D., Gassler, C. S. and Bukau, B. (2001) Advances in protein chemistry: Protein folding in the cell. Acad. Press 59, 1-44.

Mayer, M. P. and Bukau, B. (2005) Hsp70 chaperones: Cellular functions and molecular mechanism. Cell. Mol. Life Sci. 62, 670-684.

Mayer, M. P., Rudiger, S. and Bukau, B. (2000) Molecular basis of interactions of the DnaK chaperone with substrates. Biol. Chem. 381, 877-885.

Michels, A. A., Kanon, B., Bensaude, O., Konings, A. W. T. and Kampinga, H. H. (1997) HSP70 and HSP40 chaperone activities in the cytoplasm and the nucleus of mammalian cells. J. Biol. Chem. 272, 33283-33289.

Mogk, A., Tomoyasu, T., Goloubinoff, P., Rudiger, S., Roder, D., 
Langen, H. and Bukau, B. (1999) Identification of thermolabile Escherichia coli proteins: Prevention and reversion of aggregation by DnaK and ClpB. EMBO J. 18, 6934-6949.

Nollen, E. A. A., Brunsting, J. F., Roelofsen, H., Weber, L. A. and Kampinga, H. H. (1999) In vivo chaperone activity of heat shock protein 70 and thermotolerance. Mol. Cell. Biol. 19, 2069-2079.

Sambrook, J., Fritsch, E. F. and Maniatis, T. (1989) Molecular Cloning: A Laboratory Manual, $2^{\text {nd }}$ ed. Cold Spring Harbor Laboratory Press, New York.

Silberg, J. J. and Vickery, L. E. (2000) Kinetic characterization of the ATPase cycle of the molecular chaperone Hsc66 from Escherichia coli. J. Biol. Chem. 275, 7779-7786.

Silberg, J. J., Tapley, T. L., Hoff. K. G. and Vickery, L. E. (2004) Regulation of the HscA ATPase reaction cycle by the cochaperone $\mathrm{HscB}$ and the iron-sulfur cluster assembly protein IscU. J. Biol. Chem. 279, 53924-53931.

Tanaka, N., Nakao, S., Wadai, H., Ikeda, S., Chatellier, J. and Kunugi, S. (2002) The substrate binding domain of DnaK facilitates slow protein refolding. Proc. Natl. Acad. Sci. USA 99, 15398-15403.

Tatsuta, T., Tomoyasu, T., Bukau, B., Kitagawa, M., Mori, H., Karata, K. and Ogura, T. (1998) Heat shock regulation in the ftsH null mutant of Escherichia coli: Dissection of stability and activity control mechanisms of $\sigma^{32}$ in vivo. Mol. Microbiol. 30, 583-593.

Tomoyasu, T., Mogk, A., Langen, H., Goloubinoff, P. and Bukau, B. (2001) Genetic dissection of the roles of chaperones and proteases in protein folding and degradation in the Escherichia coli cytosol. Mol. Microbiol. 40, 397-413.

Tuttle, A. M. (2006) Characterization of the expression and function of Rana catesbeiana HSP30 and Xenopus laevis HSP27. M.S. thesis. University of Waterloo, Ontario.

Veinger, L., Diamant, S., Buchner, J. and Goloubinoff, P. (1998) The small heat-shock protein IbpB from Escherichia coli stabilizes stress-denatured proteins for subsequent refolding by a multichaperone network. J. Biol. Chem. 273, 11032-11037. 